Check for updates

Cite this: Mater. Adv., 2020,

1,1071

Received 29th March 2020

Accepted 11th July 2020

DOI: $10.1039 / \mathrm{d} 0 \mathrm{ma00143k}$

rsc.li/materials-advances

\section{Carbon nanotube enhanced dynamic polymeric materials through macromolecular engineering $\dagger$}

\author{
Erika B. Stopler, (D) $\ddagger^{a}$ Obed J. Dodo, (D) $\ddagger^{a}$ Alexander C. Hull, ${ }^{a}$ Kyle A. Weaver, ${ }^{a}$ \\ Progyateg Chakma, ${ }^{a}$ Richard Edelmann, ${ }^{\mathrm{b}}$ Logan Ranly, ${ }^{\mathrm{C}}$ Mehdi B. Zanjani, \\ Zhijiang $\mathrm{Ye}^{\mathrm{c}}$ and Dominik Konkolewicz (D) *a
}

\begin{abstract}
Dynamic covalent Diels-Alder chemistry was combined with multiwalled carbon nanotube (CNT) reinforcement to develop strong, tough and conductive dynamic materials. Unlike other approaches to functionalizing CNTs, this approach uses Diels-Alder bonds between diene pendant groups on the polymer and the CNT surface $\pi \sigma$ bonds acting as dienophiles. Experimental and simulation data align with the CNT reinforcement coming from dynamic covalent bonds between the matrix and the CNT surface. The addition of just 0.9 wt\% CNTs can lead to an almost 3-fold increase in strength and 6-7 order of magnitude increases in electrical conductivity, and materials with 0.45 wt\% CNTs show excellent strength, self-healing and conductivity.
\end{abstract}

Polymer materials have almost limitless applications, ranging from adhesives, through performance composites, to biomaterials. ${ }^{1,2}$ Bulk polymeric materials generally fall into the class of thermoplastic materials, which can be easily processed due to the absence of crosslinks, albeit with limited performance above a certain temperature. Alternatively, thermoset materials have excellent performance and strength at all temperatures due to their extensive crosslinking, although their (re)processability is challenging or non-existent. Dynamic bonds are able to exchange either intrinsically or in response to an external stimulus. ${ }^{3}$ Therefore, polymer materials that contain dynamic bonds have the processability of thermoplastic materials and the strength imparted by linkers and crosslinks in thermosets. In particular, dynamic covalent bonds have attracted substantial interest as

\footnotetext{
${ }^{a}$ Department of Chemistry and Biochemistry, Miami University, Oxford, $\mathrm{OH} 45056$, USA.E-mail: d.konkolewicz@miamiOH.edu

${ }^{b}$ Center for Advanced Microscopy \& Imaging, Miami University, Oxford, $\mathrm{OH} 45056$, USA

${ }^{c}$ Department of Mechanical and Manufacturing Engineering, Miami University, Oxford, OH 45056, USA

$\dagger$ Electronic supplementary information (ESI) available: Supplemental experimental procedures, transmission electron microscopy, scanning electron microscopy, size exclusion chromatography, tensile testing data, infrared, differential scanning calorimetry and creep data. See DOI: 10.1039/d0ma00143k

\$ These authors contributed equally.
}

linkers in polymeric materials due to their strong covalent bond character and their stimulus responsive nature., ${ }^{3,4}$ Diels-Alder (DA) reactions including those between furans and maleimides have received significant attention as thermoresponsive bonds and linkers in polymer materials. ${ }^{5,6}$ Nevertheless, polymer matrices alone have limited strength, functionality, and performance, which therefore encouraged the development of a method for utilizing nanocomposites to improve materials by introducing high performance nanoreinforcement. ${ }^{7-9}$ Various nanoreinforcements have been used in dynamic polymeric materials including silica, superparamagnetic nanoparticles, graphene, and carbon nanotubes (CNTs). ${ }^{9-13}$

CNTs have received significant attention due to both their strength and their electrical conductivity. ${ }^{14,15}$ Generally, the introduction of CNTs into a polymer matrix increases mechanical strength and dramatically boosts electrical conductivity, especially above the percolation threshold. ${ }^{16,17}$ CNTs have been introduced into dynamic polymer matrices in the literature, with examples of CNTs included in epoxy matrices and also vinyl polymer matrices. However, to truly gain the benefit of nanocomposite reinforcement, effective connection of the polymer to the matrix must be achieved. Traditionally, the surface of CNTs has been modified with carboxylic acid groups though harsh acidic reactions, with complex synthetic steps that limit large scale applications. ${ }^{18,19}$ However, as highlighted by Chang and Liu the $\pi$-bonds in the CNTs can react through DA processes with both dienes (such as furans) and dienophiles (such as maleimides) allowing mild, simple, in situ modification of the nanotube surface. ${ }^{20}$ This chemistry was utilized by Barner-Kowollik et al. to reversibly modify carbon nanotube surfaces. ${ }^{21-24}$

In the past two decades, reversible deactivation radical polymerization (RDRP) processes have been developed and they allow polymer architecture to be precisely designed, with excellent tolerance to chemical functionality. ${ }^{25}$ Reversible addition-fragmentation chain transfer (RAFT) polymerization is a RDRP technique with exceptional tolerance of chemical functionality and it can be performed under mild conditions. ${ }^{26}$ 
Recently, Pramanika and Singha ${ }^{27}$ utilized RAFT to create polymers with pendant furan groups that could reversibly attach to the multiwalled CNT surface, while Lim et al. ${ }^{28}$ used this approach to functionalize CNTs to improve their colloidal stability. To date, the focus has been on using the innate DA chemistry of CNTs with small molecule or polymer containing dienes and dienophiles to make colloidal or nanoscale materials. Dynamic and self-healing CNT reinforced bulk materials with the polymer matrix precisely engineered by RAFT are not well understood. Additionally, the concept of utilizing the intrinsic DA chemistry of CNTs to develop bulk scale dynamic and self-healing nanocomposites has not been explored to the best of our knowledge. This communication utilizes the ability of RAFT to control macromolecular architecture, thermoresponsive furan-maleimide (FMI) DA dynamic covalent bonding and CNT reinforcement to create strong and dynamic bulk polymer materials. This work indicates that less than $1 \mathrm{wt} \%$ CNT loading is sufficient to lead to a substantial improvement in the performance of polymer materials and to develop strong and powerful polymer materials. The excellent performance is enabled by the reversible bonding of the excess furan groups to the CNT surface, ${ }^{20}$ enabling facile and responsive bonding of the polymer matrix to the nanoscale reinforcement. Due to the thermoresponsive FMI units, the materials possess excellent dynamic character, as assessed through self-healing experiments. The advantage of the CNT based nanoscale reinforcement strategy is that it can enhance the mechanical, thermal and electrical properties of RAFT based materials while maintaining the dynamic properties imparted by the DA networks.

Well defined primary chain polymers were synthesized by RAFT polymerization, using ethyl acrylate (EA) as the main backbone forming monomer EA polymers having low glass transition temperatures, facilitating dynamic exchange under all conditions. Furfuryl methacrylate (FMA) was used to introduce the diene groups needed for dynamic covalent DA chemistry, and ethylene glycol dimethacrylate (EGDMA) was used as a static branching point. Control materials without the dynamic covalent DA units were synthesized using glycidyl methacrylate (GMA), which can form crosslinks by epoxide ring opening, without introducing substantial dynamic character to the material, or bonding to the CNT surface. All RAFT polymerizations were performed using 2-(propionic acid)yl dodecyl trithiocarbonate (PADTC) as the chain transfer agent. A typical polymer synthesis is shown in Scheme 1a. Branching can be introduced by adding 1 equivalent of EGDMA, with an otherwise identical polymerization process. The polymers were subsequently crosslinked using 1,1'-(methylenedi-4,1-phenylene) bismaleimide (BMI), since the pendant furan groups of the polymer can react with the maleimide functionality, as shown in Scheme 1b. The system will have an excess of furan groups, due to the $95 \%$ purity of the obtained $\mathrm{BMI},{ }^{29}$ allowing the excess furan to react with the CNT surface through DA chemistry, as highlighted in pink in Scheme $1 \mathrm{~b}$.

Fig. 1a shows a TEM micrograph of the multiwalled CNTs used in this project. Fig. S1 (ESI $\dagger$ ) shows the TEM images of CNTs at lower magnification. There is variability in size between
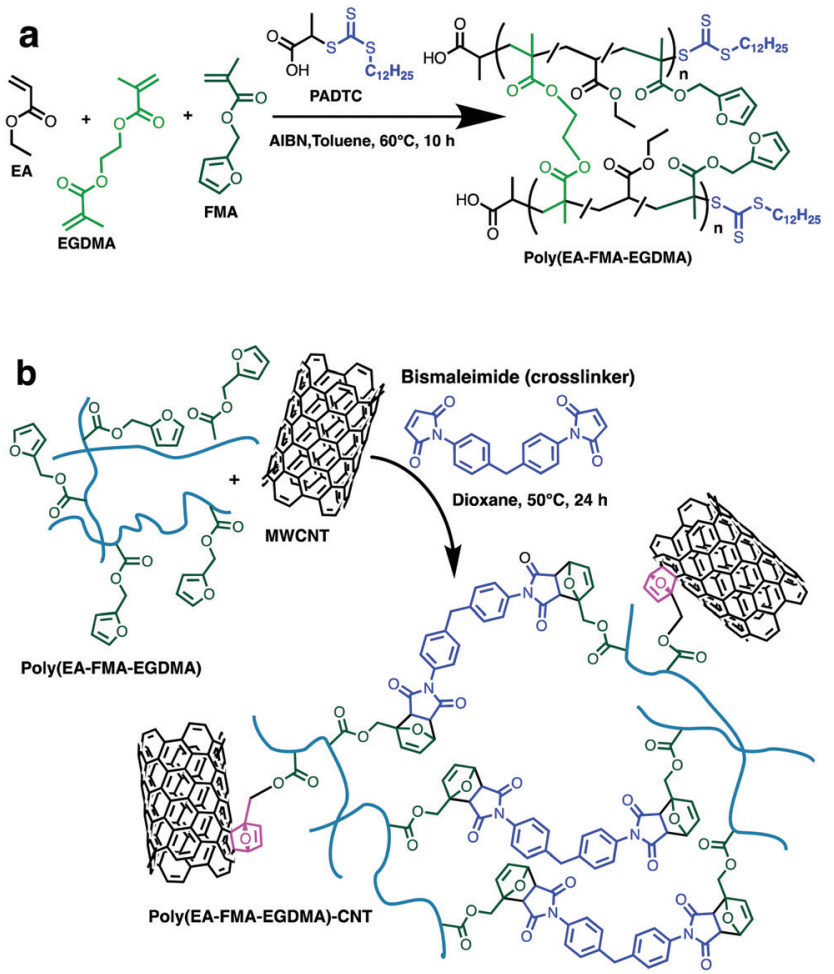

Scheme 1 (a) RAFT polymerization of EA with FMA and EGDMA to give a primary polymer bearing pendant furan groups. (b) Crosslinking of the polymer with $\mathrm{BMI}$ in the presence of CNTs to give CNT dynamic material composites.

the tubes as expected for non-fractionated CNT materials. Poly(EA) chains were synthesized with primary chain lengths of $c a .100$ units of EA and either $7 \%$ or $4.5 \%$ crosslinker. The polymers are denoted as poly $\left(\mathrm{EA}_{100}-\mathrm{FMA}_{x}\right)$-Lin for a linear polymer containing $x$ units of FMA, poly $\left(\mathrm{EA}_{100}-\mathrm{FMA}_{x}\right)-\mathrm{Br}$ for a branched polymer containing $x$ units of FMA and poly $\left(\mathrm{EA}_{100^{-}}\right.$ $\mathrm{GMA}_{x}$ )-Lin for a linear polymer containing $x$ units of GMA. Conversion and characterization data for these polymers are given in Table S1 (ESI $\dagger$ ), with the molecular weight distributions, as determined by size exclusion chromatography (SEC), given in Fig. S2 (ESI $\dagger$ ). The clear advantage of RAFT over conventional polymerization is the ability to control the primary chain length, branching degree by the addition of EGDMA and content of crosslinkers. Linear polymers were relatively well defined, while branched polymers exhibited significantly broader molecular weight distributions, as shown in Fig. S2 (ESI†).

After crosslinking the RAFT synthesized furan containing polymers using BMI, polymer network materials were obtained. GMA was crosslinked by ring opening using $N, N^{\prime}$ dimethylethylenediamine. Materials were synthesized both with and without the CNT reinforcement. The typical morphology of a material with and without CNT reinforcement was explored using scanning electron microscopy (SEM), as shown in Fig. S3 (ESI $\dagger$ ). The SEM images suggest that the majority of the materials with and without CNTs have similar morphologies (Fig. S3A and B, ESI $\dagger$ ), although there are certain domains with higher densities of CNTs and this may be due to the 

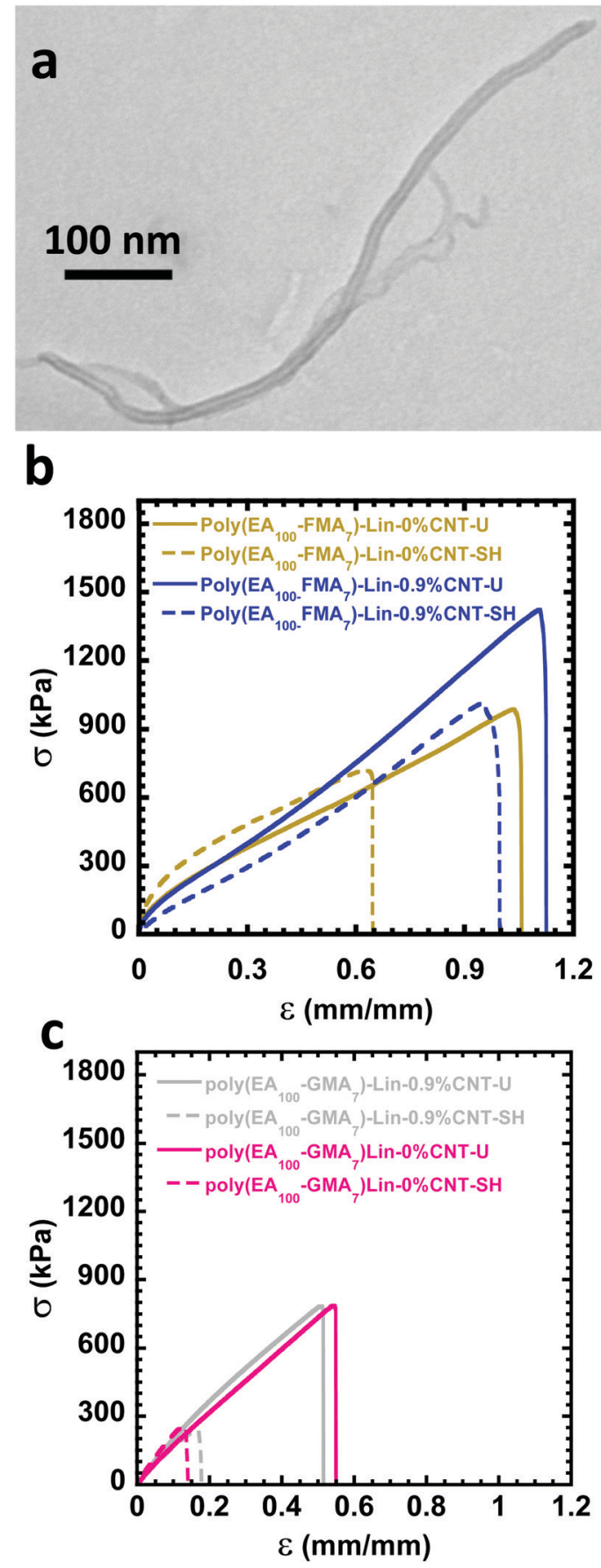

Fig. 1 (a) TEM micrograph of typical carbon nanotubes used in this study. (b) Stress-strain curve of poly $\left(E_{100}-F M A_{7}\right)$-Lin uncut and $24 \mathrm{~h}$ healed at $75{ }^{\circ} \mathrm{C}$ materials, including materials with and without 0.9 wt\% CNTs. (c) Stress-strain curve of poly $\left(E_{100}-G_{1 M A}\right)$-Lin uncut and $24 \mathrm{~h}$ healed at $75{ }^{\circ} \mathrm{C}$ materials, including materials with and without $0.9 \mathrm{wt} \% \mathrm{CNTs}$.

dispersion of CNTs during synthesis (Fig. S3C, ESI $\dagger$ ). However, the vast majority of the materials have similar morphologies and the CNTs are visibly dispersed throughout the structure (Fig. S3B, ESI $\dagger$ ).

Each material was characterized using tensile testing, infrared spectroscopy (IR), differential scanning calorimetry (DSC) and dynamic mechanical thermal analysis (DMTA). Typical IR spectra are shown in Fig. S4 (ESI $\dagger$ ) with the assignment given in Table S2 (ESI $\dagger$ ). Interestingly, the material in Fig. S4 (ESI $\dagger$ ) containing $0.9 \mathrm{wt} \%$ CNTs exhibited stronger absorbance in the alkene stretching region from 1600 to $1500 \mathrm{~cm}^{-1}$ and stronger absorbance attributed to the addition of $\pi$-bonds from the CNTs. The difference is small due to the loading of CNTs being $<1 \mathrm{wt} \%$. The slightly stronger absorbance near $1651 \mathrm{~cm}^{-1}$ could be due to the DA adduct of furan groups on the CNT surface, ${ }^{20}$ although the low mass fraction of CNTs limits conclusive assignment.

Glass transition temperatures were obtained by DSC and are reported in Table 1 with a typical DSC curve shown in Fig. S5 (ESI $\dagger$ ). All glass transition temperatures were close to $0{ }^{\circ} \mathrm{C}$, implying that all materials will be soft at room temperature. Each material was subjected to thermogravimetric analysis (TGA), with the TGA degradation profile shown in Fig. S6 (ESI $\dagger$ ). Each material had a similar degradation profile with the onset of degradation occurring in the range of $320-340{ }^{\circ} \mathrm{C}$. This is most likely due to the bulk of each material being poly(EA). Typical tensile curves are shown in Fig. S7-S16 (ESI $\dagger$ ), with average strain at break $\left(\varepsilon_{\text {break }}\right)$ and peak stress $\left(\sigma_{\text {peak }}\right)$ values given in Table 1.

Initially, $0.9 \mathrm{wt} \%$ CNTs were utilized to determine if even a small CNT loading $(<1 \mathrm{wt} \%)$ could give rise to powerful enhancements in the electrical and mechanical properties of the materials. Fig. $1 \mathrm{~b}$ indicates that $0.9 \mathrm{wt} \%$ CNTs was sufficient to lead to a noticeable strengthening of the poly $\left(\mathrm{EA}_{100^{-}}\right.$ $\mathrm{FMA}_{7}$ )-Lin material along with an increase in toughness. As shown in Fig. 1c, the 0.9 wt\% CNT loading had a negligible effect on the mechanical properties of poly $\left(\mathrm{EA}_{100}-\mathrm{GMA}_{7}\right)$-Lin control materials crosslinked with the GMA linker, which should have minimal dynamic character, and a negligible ability to attach to the CNT surface.

The difference between the mechanical properties of the poly $\left(\mathrm{EA}_{100}-\mathrm{GMA}_{7}\right)$-Lin control and the poly $\left(\mathrm{EA}_{100}-\mathrm{FMA}_{7}\right)$-Lin material is most likely due to the furan units in the poly $\left(\mathrm{EA}_{100}-\mathrm{FMA}_{7}\right)$-Lin material attaching to the surface of the nanotubes, allowing efficient load transfer between the matrix and the CNT reinforcement. In contrast, the poly $\left(\mathrm{EA}_{100}-\mathrm{GMA}_{7}\right)$ Lin material cannot bind efficiently to the nanotubes through DA chemistry, and therefore load transfer is likely poorer between the matrix and the reinforcement. Therefore, the comparison of the DA active poly $\left(\mathrm{EA}_{100}-\mathrm{FMA}_{7}\right)$-Lin material, which can bind the matrix covalently to the nanotubes, and the control material, poly $\left(\mathrm{EA}_{100}-\mathrm{GMA}_{7}\right)$-Lin, which cannot efficiently bind to the nanotubes, highlights the importance of enabling the binding of the polymer matrix to the CNT surface. In the absence of covalent bonding between the matrix and the reinforcement, the nanotubes are unable to effectively have the load transferred to them as only sterics connect the matrix to the CNTs.

The presence of thermoresponsive FMI adducts led to effective self-healing after heating to $75{ }^{\circ} \mathrm{C}$ for $24 \mathrm{~h}$ of the poly $\left(\mathrm{EA}_{100}-\mathrm{FMA}_{7}\right)$-Lin materials both with and without CNTs, while much poorer recovery of mechanical properties was observed in the poly $\left(\mathrm{EA}_{100}-\mathrm{GMA}_{7}\right)$-Lin control materials. The 
Table 1 Mechanical and thermal properties of unreinforced and CNT reinforced materials

\begin{tabular}{|c|c|c|c|c|c|}
\hline Polymer & Wt $\%$ CNTs & $T_{\mathrm{g}}\left({ }^{\circ} \mathrm{C}\right)$ & $\sigma_{\text {peak }}(\mathrm{MPa})$ & $\varepsilon_{\text {break }}(\mathrm{mm} / \mathrm{mm})$ & $Y(\mathrm{MPa})$ \\
\hline Poly $\left(\mathrm{EA}_{100}-\mathrm{FMA}_{7}\right)$-Lin & 0.9 & -1 & $1.29 \pm 0.06$ & $0.9 \pm 0.08$ & $1.8 \pm 0.3$ \\
\hline Poly $\left(\mathrm{EA}_{100}-\mathrm{GMA}_{7}\right)$-Lin & 0 & -5 & $0.83 \pm 0.04$ & $0.59 \pm 0.04$ & $1.80 \pm 0.03$ \\
\hline Poly $\left(\mathrm{EA}_{100}-\mathrm{FMA}_{7}\right)-\mathrm{Br}$ & 0 & -1 & $1.03 \pm 0.06$ & $0.81 \pm 0.03$ & $2.3 \pm 0.2$ \\
\hline Poly $\left(\mathrm{EA}_{100}-\mathrm{FMA}_{7}\right)-\mathrm{Br}$ & 0.225 & 2 & $1.32 \pm 0.09$ & $0.94 \pm 0.03$ & $2.46 \pm 0.09$ \\
\hline Poly $\left(\mathrm{EA}_{100}-\mathrm{FMA}_{7}\right)-\mathrm{Br}$ & 0.45 & 2 & $2.2 \pm 0.3$ & $0.79 \pm 0.04$ & $5.6 \pm 0.7$ \\
\hline $\operatorname{Poly}\left(\mathrm{EA}_{100}-\mathrm{FMA}_{4.5}\right)-\mathrm{Br}$ & 0.9 & -5 & $0.54 \pm 0.05$ & $0.97 \pm 0.08$ & $0.66 \pm 0.03$ \\
\hline
\end{tabular}

non-zero recovery of poly( $\left.\mathrm{EA}_{100}-\mathrm{GMA}_{7}\right)$-Lin control materials can be attributed to the small number of $\mathrm{H}$ bonding units introduced after ring opening of the epoxide in GMA by the diamine. $^{30}$ Additionally, the CNT containing materials had superior electrical conductivity. The materials without added CNTs had no measurable conductivity, with the estimated conductivity $(\kappa)$ of $10^{-9} \pm 10^{-9} \mathrm{~S} \mathrm{~m}^{-1}$ based on the literature reported conductivities of related polymers of poly(methyl methacrylate), which is an isomer of poly(EA) and poly(ethyl methacrylate), which has one added methyl group. ${ }^{31,32}$ In contrast, the poly $\left(\mathrm{EA}_{100}-\mathrm{FMA}_{7}\right)$-Lin material had $\kappa=(1.0 \pm$ $0.7) \times 10^{-2} \mathrm{~S} \mathrm{~m}^{-1}$ and the poly $\left(\mathrm{EA}_{100}-\mathrm{GMA}_{7}\right)$-Lin material had $\kappa=(5 \pm 2) \times 10^{-2} \mathrm{~S} \mathrm{~m}^{-1}$. These values represent $6-7$ orders of magnitude improvements in electrical conductivity due to the presence of just $0.9 \mathrm{wt} \%$ CNT loading.

Branching is a powerful parameter that can enhance material properties. The addition of 1 equivalent of a divinyl monomer such as EGDMA can create highly branched polymers. ${ }^{33}$ Interestingly, the poly $\left(\mathrm{EA}_{100}-\mathrm{FMA}_{7}\right)-\mathrm{Br}$ materials synthesized with 1 equivalent of EGDMA to CTA show a remarkable enhancement in mechanical properties. A similar enhancement is observed in poly $\left(\mathrm{EA}_{100}-\mathrm{FMA}_{4.5}\right)-\mathrm{Br}$, albeit starting from a weaker material at a lower crosslink density (Table 1). Fig. 2 and Table 1 show that, with just $0.9 \mathrm{wt} \%$ CNT loading, the peak stress in these materials is enhanced by a factor of 3 compared to the unreinforced materials. The conductivity of the poly $\left(\mathrm{EA}_{100}-\mathrm{FMA}_{7}\right)-\mathrm{Br}$ material with 0.9 wt $\%$ CNTs was $\kappa=(4.7 \pm 0.4) \times 10^{-2} \mathrm{~S} \mathrm{~m}^{-1}$.

As the nanotube loading was decreased to 0.45 and 0.225 wt\% CNTs, the extent of mechanical reinforcement and electrical conductivity also decreased, as demonstrated in Fig. 2a. Importantly, the data in Fig. 2a indicate that all materials display self-healing characteristics. The very stiff 0.9 wt $\%$ loaded material exhibited relatively little self-healing, while the 0.45 and $0.225 \mathrm{wt} \% \mathrm{CNT}$ loaded materials exhibited relatively similar self-healing $(\mathrm{SH})$ recovery compared to the uncut materials (U).

Due to the superior performance of the CNT reinforced materials based on poly $\left(\mathrm{EA}_{100}-\mathrm{FMA}_{7}\right)-\mathrm{Br}$, all subsequent analyses focused on these systems. A possible reason for the superior performance of poly $\left(\mathrm{EA}_{100}-\mathrm{FMA}_{7}\right)-\mathrm{Br}$ compared to the linear equivalents is that the branching can lead to an overall larger polymer chain with more FMA units. This could allow the matrix to better bridge and attach to multiple CNT reinforcements, enabling efficient load transfer in the polymer material.
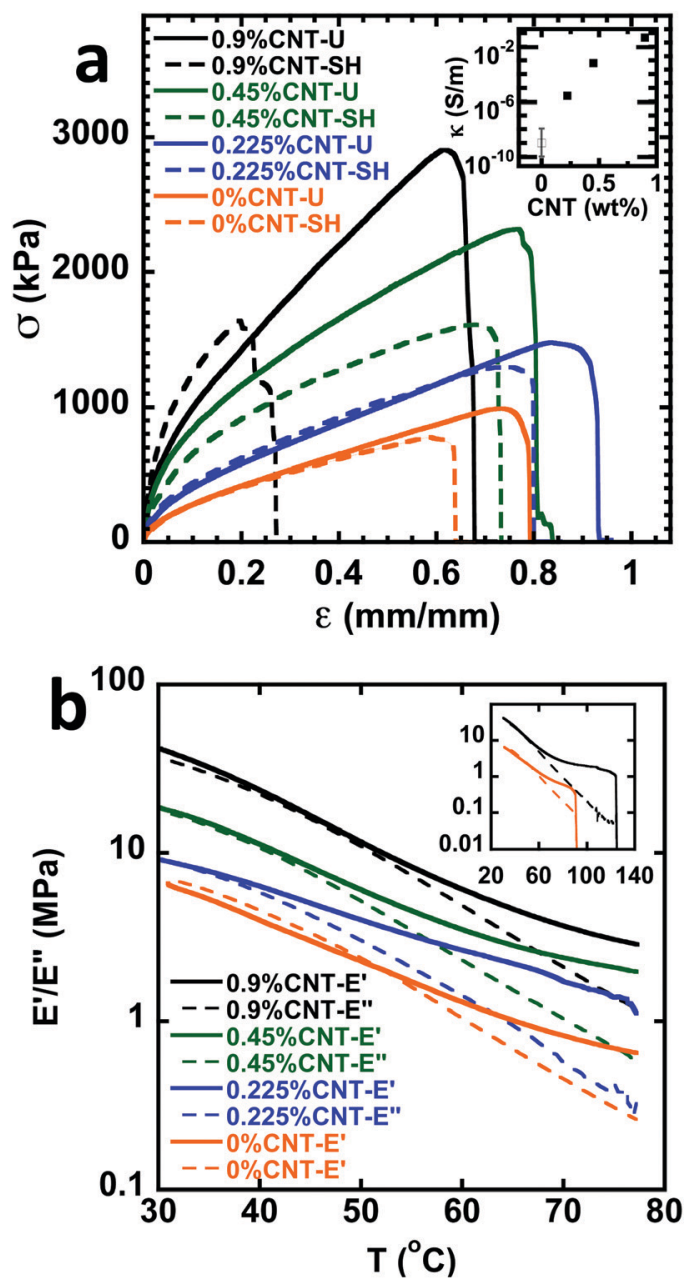

Fig. 2 (a) Typical stress $(\sigma)$-strain $(\varepsilon)$ curves for both uncut $(U)$ and selfhealed (SH) poly $\left(E_{100}-F M A_{7}\right)-B r$ materials with different loadings of CNTs. Inset: Electrical conductivity $(\kappa)$ vs. CNT weight content in the material. (b) Temperature sweep data for poly $\left(E_{100}-F M A_{7}\right)-B r$ materials with different loadings of CNTs. Inset: Full range of data for 0.9 and $0 \mathrm{wt} \%$ CNT loadings.

Electrical percolation, compared to mechanical reinforcement, is less impacted by chain bridging, which could explain why the conductivity of the poly $\left(\mathrm{EA}_{100}-\mathrm{FMA}_{7}\right)-\mathrm{Br}$, poly $\left(\mathrm{EA}_{100}-\mathrm{FMA}_{7}\right)-\mathrm{Lin}$ and poly $\left(\mathrm{EA}_{100}-\mathrm{GMA}_{7}\right)$-Lin materials with $0.9 \mathrm{wt} \% \mathrm{CNTs}$ is in the same order of magnitude, despite the superior mechanical properties of poly $\left(\mathrm{EA}_{100}-\mathrm{FMA}_{7}\right)-\mathrm{Br}$. 


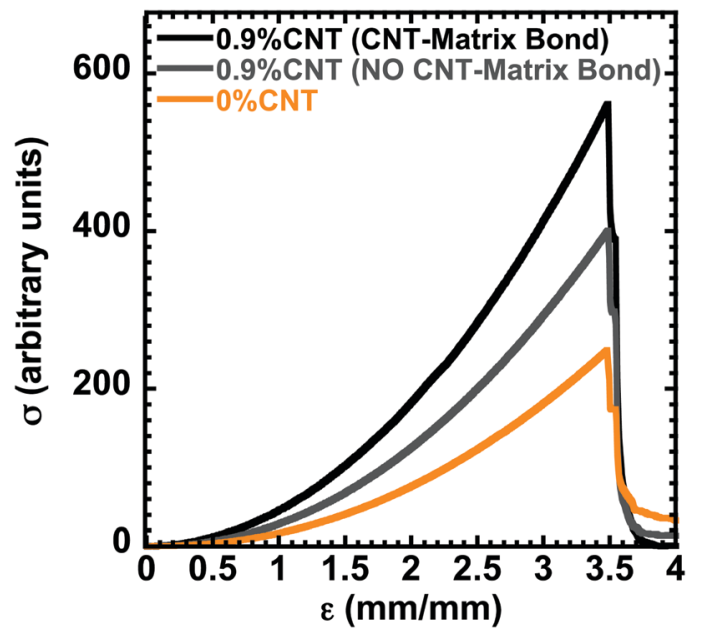

Fig. 3 Simulated stress-strain curve for the polymer matrix containing primary chain lengths of 100 and $7 \%$ furan groups. 95\% furan groups are crosslinked as part of the matrix. The orange curve represents the matrix only, the grey curve is the matrix with 0.9 wt\% CNTs, with the CNTs dispersed but not bonded to the matrix, while the black curve shows the polymer matrix covalently bonded to $0.9 \mathrm{wt} \%$ CNTs.

Fig. 2b shows the dynamic mechanical thermal analysis (DMTA) profiles over the range of $30-80{ }^{\circ} \mathrm{C}$. The DMTA data show a thermal transition to a rubbery plateau followed by eventual disintegration of the material as the DA crosslinks dissociate. Interestingly, the inset of Fig. $2 \mathrm{~b}$ shows that poly $\left(\mathrm{EA}_{100}-\mathrm{FMA}_{7}\right)$-Br with 0.9 wt $\%$ CNTs can reach much higher temperatures before the DA bond dissociation causes the material to fail compared to poly $\left(\mathrm{EA}_{100}-\mathrm{FMA}_{7}\right)-\mathrm{Br}$ with $0 \mathrm{wt} \%$ CNTs. The higher storage modulus is also reflected in the frequency sweep data in Fig. S17 (ESI $\dagger$ ). All materials exhibited limited creep and good creep recovery, as indicated in Fig. S18 (ESI $\dagger$ ). This is consistent with the DA units being essentially fixed at temperatures near ambient.

Finally, to confirm the impact of the polymer-matrixnanotube reinforcement, molecular dynamics (MD) simulations were performed. MD simulations were used to evaluate the mechanical properties of the polymer matrix, the polymer matrix with nanotubes, and the matrix with covalent bonds between the nanotubes and the matrix. A coarse-grained model for the polymers and cross-linkers ${ }^{34}$ was used with polymer chains made up of 100 beads, interconnected through covalently bonded furan-maleimide crosslinkers. There are 7 linkers introduced per polymer chain to represent the $7 \%$ cross-linkers present in the experimental setup. Additionally, the CNTs were modelled as rigid cylinders formed by a number of beads (similar in size to the polymer beads) that provide a cylinder of $20 \mathrm{~nm}$ diameter. For simplicity and convenience of the model, the carbon nanotube length was set as equivalent to 200 bead diameters, and the number of carbon nanotubes (cylinders) in the simulation box was selected in a way to provide $0.9 \%$ total mass of the system, comparable to the experimental value. The crosslinker was based on furan-maleimide DA adducts developed earlier. ${ }^{34}$ The simulation approach and a snapshot from the simulation are presented in Fig. S19 (ESI $\dagger)$.
As indicated in Fig. 3, the simulated stress-strain curve of the polymer matrix reaches an $\varepsilon_{\text {break }}$ of $c a$. 3.5, with a $\sigma_{\text {peak }}$ of $c a$. 250 a.u. The introduction of $0.9 \mathrm{wt} \%$ CNTs led to a slight increase in peak stress, when the CNTs are not bonded to the matrix. Significant mechanical reinforcement is only realized in the presence of CNTs that are bonded to the matrix. This implies that the pendant furan groups of the matrix need to be bonded to the CNTs to realize the substantial mechanical enhancements observed experimentally in Fig. 1 and 2. This is likely due to the covalent bonding between the matrix and the CNTs leading to effective transfer of load between the matrix and the reinforcement.

In conclusion, a series of dynamic and self-healing polymer materials was synthesized and reinforced with multiwalled carbon nanotubes (CNTs). The use of dynamic covalent DA chemistry using furans and maleimides enabled the synthesis of self-healing polymer matrices and CNT composites. Experimental and simulation data suggest that the unreacted furan groups in the matrix bond to the CNT surface, leading to substantial enhancements in material strength and toughness. After the introduction of just $0.9 \mathrm{wt} \%$ CNTs, the stress at break values can increase by 2.7 -fold to over $3 \mathrm{MPa}$, compared to the unreinforced materials in the branched matrices. In addition to mechanical reinforcement, electrical conductivity was dramatically increased by the addition of CNTs.

\section{Author contributions}

The manuscript was written with contributions from all authors. All authors have given approval to the final version of the manuscript.

\section{Conflicts of interest}

The authors declare no competing interest.

\section{Acknowledgements}

We greatly appreciate experimental assistance from Zachary Digby, Nethmi DeAlwis, Jeremy Via, Michael Duffy and Andre J Sommer. This material is based upon work supported by the National Science Foundation under Grant No. DMR-1749730. Dominik Konkolewicz would also like to acknowledge the support from the Robert H. and Nancy J. Blayney Professorship. The authors acknowledge computational resources of the Ohio Supercomputer Center through Award No. PMIU0139.

\section{References}

1 S. Ramakrishna, J. Mayer, E. Wintermantel and K. W. Leong, Compos. Sci. Technol., 2001, 61, 1189.

2 M. A. C. Stuart, W. T. S. Huck, J. Genzer, M. Müller, C. Ober, M. Stamm, G. B. Sukhorukov, I. Szleifer, V. V. Tsukruk, M. Urban, F. Winnik, S. Zauscher, I. Luzinov and S. Minko, Nat. Mater., 2010, 9, 101.

3 P. Chakma and D. Konkolewicz, Angew. Chem., Int. Ed., 2019, 58, 9682. 
4 W. Zou, J. Dong, Y. Luo, Q. Zhao and T. Xie, Adv. Mater., 2017, 29, 1606100.

5 G. Hizal, U. Tunca and A. Sanyal, J. Polym. Sci., Part A: Polym. Chem., 2011, 49, 4103.

6 X. Chen, M. A. Dam, K. Ono, A. Mal, H. Shen, S. R. Nutt, K. Sheran and F. Wudl, Science, 2002, 295, 1698.

7 O. Breuer and U. Sundararaj, Polym. Compos., 2004, 25, 630.

8 J. Jordan, K. I. Jacob, R. Tannenbaum, M. A. Sharaf and I. Jasiuk, Mater. Sci. Eng., A, 2005, 393, 1.

9 T. Engel and G. Kickelbick, Polym. Int., 2014, 63, 915.

10 V. K. Thakur and M. R. Kessler, Polymer, 2015, 69, 369.

11 C. C. Corten and M. W. Urban, Adv. Mater., 2009, 21, 5011.

12 X. Xiao, T. Xie and Y.-T. Cheng, J. Mater. Chem., 2010, 20, 3508.

13 Z. Spitalsky, D. Tasis, K. Papagelis and C. Galiotis, Prog. Polym. Sci., 2010, 35, 357.

14 N. Behabtu, C. C. Young, D. E. Tsentalovich, O. Kleinerman, X. Wang, A. W. K. Ma, E. A. Bengio, R. F. ter Waarbeek, J. J. de Jong, R. E. Hoogerwerf, S. B. Fairchild, J. B. Ferguson, B. Maruyama, J. Kono, Y. Talmon, Y. Cohen, M. J. Otto and M. Pasquali, Science, 2013, 339, 182.

15 M. M. Shokrieh and R. Rafiee, Mech. Compos. Mater., 2010, 46, 155.

16 W. Bauhofer and J. Z. Kovacs, Compos. Sci. Technol., 2009, 69, 1486.

17 J. N. Coleman, U. Khan, W. J. Blau and Y. K. Gun'ko, Carbon, 2006, 44, 1624.

18 P. Liu, Eur. Polym. J., 2005, 41, 2693.

19 S. Bose, R. A. Khare and P. Moldenaers, Polymer, 2010, 51, 975.

20 C.-M. Chang and Y.-L. Liu, Carbon, 2009, 47, 3041.
21 N. Zydziak, C. M. Preuss, V. Winkler, M. Bruns, C. Hübner and C. Barner-Kowollik, Macromol. Rapid Commun., 2013, 34, 672 .

22 N. Zydziak, C. Hübner, M. Bruns and C. Barner-Kowollik, Macromolecules, 2011, 44, 3374.

23 B. Yameen, N. Zydziak, S. M. Weidner, M. Bruns and C. Barner-Kowollik, Macromolecules, 2013, 46, 2606.

24 N. Zydziak, C. Hübner, M. Bruns, A. P. Vogt and C. BarnerKowollik, Polym. Chem., 2013, 4, 1525.

25 W. A. Braunecker and K. Matyjaszewski, Prog. Polym. Sci., 2007, 32, 93.

26 S. Perrier, Macromolecules, 2017, 50, 7433.

27 N. B. Pramanik and N. K. Singha, RSC Adv., 2015, 5, 94321.

28 C. M. Q. Le, X. T. Cao, Y. T. Jeong and K. T. Lim, J. Ind. Eng. Chem., 2018, 64, 337.

29 Millipore-Sigma 1,1'-(Methylenedi-4,1-phenylene)bismaleimide Specification Sheet. https:/www.sigmaaldrich.com/Graphics/ COfAInfo/SigmaSAPQM/SPEC/22/227463/227463-BULK_ ALDRICH_.pdf, accessed Oct 272019.

30 B. Zhang, Z. A. Digby, J. A. Flum, P. Chakma, J. M. Saul, J. L. Sparks and D. Konkolewicz, Macromolecules, 2016, 49, 6871.

31 H. M. Kim, K. Kim, S. J. Lee, J. Joo, H. S. Yoon, S. J. Cho, S. C. Lyu and C. J. Lee, Curr. Appl. Phys., 2004, 4, 577.

32 C. A. Grimes, C. Mungle, D. Kouzoudis, S. Fang and P. C. Eklund, Chem. Phys. Lett., 2000, 319, 460.

33 B. Liu, A. Kazlauciunas, J. T. Guthrie and S. Perrier, Macromolecules, 2005, 38, 2131.

34 M. B. Zanjani, B. Zhang, B. Ahammed, J. P. Chamberlin, P. Chakma, D. Konkolewicz and Z. Ye, Macromol. Theory Simul., 2019, 28, 1900008. 